\title{
GEOGRAFII TEATRALE PE FIRUL ISTORIEI ȘI AL RÂULUI (I): TAMISA LA LONDRA
}

\author{
Cristian Stamatoiu
}

DOI 10.46522/CT.2020.02.02

\begin{abstract}
Theatrical Geographies Alongside the History and the River

(I): the Thames at London
\end{abstract}

The Antique settlement of Londinium became, under the name of London, a center of medieval civilization which later came to know an original way to cultivate the continental Renaissance. An item of this assimilation process was the evolution of the local primary spectacology towards the Elizabethan theatre and next, to the king Jacob I's époque. The liaison between these was ensured by the sons of two artisans (a carpenter and a glover, formerly a mayor!) from Stratford-on-Avon: John Burbage and William Shakespeare, who also determine the geography of the theaters on the two banks of the River Thames at London.

\section{Keywords}

Shakespeare, Burbage, The Globe, Queen Elisabeth I, King Jacob I

Teatrul londonez și fiii a doi meseriași din Startford-on-Avon

ădăcinile reprezentărilor dramatice londoneze coboară până la tentativa nereușită, se pare, din 1567 (aprox.) a lui James Burbage. El era originar, poate nu întâmplă- 
tor, din Stratford-upon-Avon (!) unde fusese tâmplar, pentru a deveni apoi maestru de succes în circurile de la Londra, în dresurile de câini, tauri și urși. Finanțat de cumnatul său, Bryne, el construiește din temelii după propriile-i planuri teatrul „Red Lion“, ridicat în estul Londrei, pe locul unei ferme cu același nume. Acea clădire repede abandonată va deveni însă un model arhitectonic pentru urmașele sale renascentiste. În formă de bastion, ea adăpostea o scenă cu o deschidere de 12 $\mathrm{m}$, o adâncime de $9 \mathrm{~m}$, înălțime de $1,5 \mathrm{~m}$., peste ea ridicându-se un turn de $9 \mathrm{~m}^{1}$. Acolo, trupa „Leicester Men“ trebuia să se dea o reprezentație, cu o dramatizare după povestea personajului biblic Samson. Numai că nu există mărturii care să ateste punerea în practică a acestei inițiative, așa că a rămas ca Londra să se mulțumească aproape încă un deceniu cu distracțiile mărunte performate, însă, cu destulă ritmicitate și profesionalism în curțile unor hanuri (household inn - en.), precum: Bell Savage, The Bull, Cross Key..., chiar dacă și astfel manifestări cădeau sub interdicțiile Primăriei, pentru că provocau mari dezordini publice.

Iar aceasta, până când aceiași doi asociați s-au orientat spre o altă zonă îndepărtată de pe malul drept al Tamisei, tocmai pentru a fi cât mai departe de vigilența gărzilor. Era vorba de zona fostei (sub)abații Priory (azi - în centrul Londrei, la aproximativ un kilometru nord față de Bridge și Tower), desființată în timpul prigoanei anticatolice, duse sistematic de către Henric al VIII-lea; acolo se mai găsea lângă câmpul Fisnbury din zona Shoredich clădirea părăsită a mănăstirii Blackfriars. Așa stând lucrurile, Brayne și Burbage au cesionat locul pentru 21 de ani, începând cu 1576. Acolo, s-a amenajat sala Blackfriars pentru spectacole, repetiții de coruri de copii sau pentru partide de tenis (!). În 1596, Burbage a mai achiziționat o incintă alăturată, transformând întregul într-un adevărat ansamblu teatral. Dar, James va deceda după un an, așa că administrarea noului Blackfriars va reveni fi-

1. Peter Thomson, „English Renaissance and Restoration Theatre“ [Teatrul englezesc al Renașterii și al Restaurației], în: John Russell Brown, The Oxford Illustrated History of the Theatre [Istoria ilustrată Oxford a teatrului], Oxford, Oxford University Press, 2001, p. 178, 180, aici și urm. 
ului său: Richard Burbage, care va contura - în concurență acerbă cu Alleyn - vârful artei scenice în epoca elisabetană. Spre deosebire de alte incinte contemporane destinate amuzamentului spectacular denumite playhouse ori circuri, James Burbage își intitulase ansamblul „poligonului cu trei galerii“: The Theatre. Iar aceasta, tocmai spre a-și afirma intenția artistică nobilă și descendența culturală din moștenirea Antichității și a Renașterii.

Numai că, datorită comportamentului necontrolat al publicului la astfel de spectacole, vecinii protestaseră pe lângă Primărie care interzisese orice reprezentație. Richard, fiul fondatorului, va obține însă protecția regală și, având dreptul de a-și numi de acum fosta trupă „The King's Men“, va putea să-și continue activitatea, având marele avantaj de a da reprezentații și iarna, sala fiind acoperită în întregime. De aici provenea și tariful de intrare considerat foarte mare: pe când la teatrul Globe se va putea intra cu un penny, aici era nevoie deja de șase astfel de monede...

Timp de un secol după The Theatre (Blackfriars), celelalte teatre londoneze au fost amplasate pe același mal drept al Tamisei. Iar aceasta, deși nu fusese abrogată oficial o ordonanță dată încă din 1575, care ar fi trebuit să interzică astfel de construcții, iar cele existente ar fi trebuit fi mutate extravilan, adică pe malul stâng al Tamisei (azi, de asemenea, centrul Londrei)! Dar, beneficiind de îngăduința reginei Elisabeta I și a succesorului ei, Jacob I, astfel de așezăminte au apărut totuși pe malul drept: Curtain (1577), Fortune (1600 și 1623), Red Bull (1605), Whitefriars (1605), Phoenix / Cockpit pe Drury Lane (1617), Salsbury Court (1629) ${ }^{2}$.

Teatrul Blackfriars era deci amplasat în cartierul Shoreditch, pe pământurile lui onorabilului Giles Allen, cu care se stabilise un contract de cesiune pe 21 de ani. Așa că, la ex-

2. Map of London Showing the Playhouses [Hartă a Londrei cu locația teatrelor], gravură de epocă, apud „The Project Gutenberg eBook“, Shakespearian Playhouses, de Quncy Adams, foto: C. W. Redwood, formel technical artist at Cornell University, http://upload.wikimedia.org/wikipwdia/commons/a/a4/London_map_showing_Shakesperean_theatres.png, la 10.01.2020. 
pirarea termenului în 31 decembrie 1598, proprietarul avea acum pretenția de a intra atât în posesia pământului, cât și a clădirii teatrului! Dar, în timp ce el își savura cu ocazia Sărbătorilor de Iarnă reușita „afacerii“, artiștii din „King’s Men“ au demontat bârnele teatrului și, profitând de o iarnă geroasă care făcuse Tamisa să înghețe, le-au tras cu caii pe malul stâng dinspre Southwark, care ținea de o altă jurisdicție financiară ${ }^{3}$. Acolo, a fost ridicat și prin investiția lui William Shakespeare teatrul Globe pe o locație apropiată de aceea pe care se regăsește astăzi o replică-muzeu a sa - 1599. Titulatura sa se pare că provine de la o sintagmă a lui Petronius apreciată în epocă, și anume: „lumea este o scenă“, motiv literar care 1-a marcat în mod deosebit și pe Shakespeare, de exemplu în comedia Cum vă place.

Mai în jos pe malul stâng al Tamisei, se afla pe atunci și prima arenă pentru jocurile cu urși, astăzi pe acel loc se găsindu-se Muzeul „Tate“. Lor i s-au alăturat apoi și alte noi teatre, precum: Rose (1587), Swann (1595) și Hope (1613). Richard Burbage va reveni însă pe malul drept al Tamisei, unde va reuși să continue, sub un alt aranjament contractual, activitatea teatrală la Blackfriars până în 1642, când Parlamentul-Coadă emite o lege de interzicere a activității tuturor teatrelor din cauza depravării ce înflorea în jurul lor.

The Globe avea o secțiune în plan „octogonală“, ce o nuanța pe cea poligonală a fostului Blackfriars, „prezentându-se la exterior ca un turn cu acoperiș de paie, având în vârf steagul companiei. În interior, erau trei rânduri de galerii circulare acoperite, rezervate spectatorilor așezați pe bănci. Scena, o platformă înaltă de un metru și jumătate, cu un acoperiș deasupra, înainta în curtea interioară, înconjurată de spectatorii ce asistau în picioare." Activitatea de acolo era, de asemenea, extrem de bine organizată: „Ziua începea cu repetiții, de la ora opt dimineața până la miezul zilei. După prânz, la unu sau la două, începea spectacolul care dura trei sau patru ore. La sfârșitul spectacolului urma o mică pauză, în timpul căreia actorii aranjau costumele și făceau ordine în cabinele tea-

3. Peter Thomson, „English Renaissance and Restoration Theatre“. 
trului. Uneori, mai dădeau o reprezentație de seară în locuințele spectatorilor privați. Atunci costumele și recuzita erau așezate în coșuri și încărcate într-o căruță sau într-o barcă ce cobora pe Tamisa“. ${ }^{4}$

\section{Will-on-Avon la Londra și înapoi}

În această lume agitată va fi apărut un mărunt outsider pe la 1587 - 1588. Era vorba de William Shakespeare (1564 - 1616), fiul unui mânușar și fost primar în Stratford-on-Avon. Tânărul fugise la Londra, părăsindu-și familia împovărătoare, în momentul în care constatase că n-ar mai fi avut un viitor luminous, dacă ar fi rămas acasă. Încercând să-și împlinească năzuințele erotice, dar fără a-și fi asumat vreo obligație socială, adolescentul de 18 ani William s-a orientat către Ann Hathaway, descendentă a unei familii de fermieri din sătucul învecinat Shottery. Aceasta avea pe atunci 26 de ani, fiind considerată în mentalitatea timpului deja fată bătrână, deci nemaiavând pretenții de mariaj. Numai că perspectiva apariției unui copil din această legătură a condus la o căsătorie grăbită, în urma căreia s-au născut două fete și un băiat mijlociu - Hamnet - care a murit însă timpuriu (totuși, după ce tatăl său plecase la Londra, ceea ce i-ar fi putut declanșa acestuia din urmă un sentiment de culpabilitate, transfigurat cel mai evident în drama Hamlet, dar, posibil și în alte creații care valorificau artistic complexul oedipian). Toate aceste complicații personale surveneau pe fundalul degradării stării financiare a întregii familii Shakespeare, mai ales după ce tatăl lui William nu a mai fost primar, iar afacerile sale cu mânuși au ajuns la faliment. Aflat într-un impas major pe toate planurile vieții sale din Stratford-on-Avon, William Shakespeare ia distanță la propriu și la figurat față de toate obligațiile pe care singur și le crease, refugiindu-se într-un anonimat londonez, unde a încercat să se reinventeze.

4. Eugenio Barba și Nicola Savese, Cele cinci continente ale teatrului. Fapte și legende din cultura materială a actorului, traducere din limba italiană de Vlad Russo, București, Nemira, 2018, p. 112, aici și urm. 
Sosit în capitală, provincialul Will se adresează în mod natural unui consătean căruia i se permisese să fondeze primul teatru londonez, James Burbage, care îl va ajuta cu slujbe mărunte de pe lângă teatrul Blackfriars: de la îngrijitul cailor și curățatul grajdului, el a fost „avansat" la întreținerea clădirii și la pregătirea costumelor, iar apoi, ca sufleor, putea face și figurație. Oarecum nemulțumit, Shakespeare se orientează ulterior spre ocupații intelectuale, pentru care avea pregătire și înclinație: meseriile de tipograf și copist.

Lăsându-se atras până la urmă tot de atmosfera teatrului, Shakespeare a reintrat, cu sprijinul lui James Burbage, în mecanismul de producere al pieselor de teatru, asigurând corectarea și adaptarea unor texte dramatice. În această ipostază, dar și în aceea de actor, el va activa apoi cu „The King's Men“ la Blackfriars. Talentul său în tratarea textului dramatic a fost repede observat de conducere, astfel încât i s-a încredințat în mod curent realizarea unor texte dramatice în întregul lor. Numai că Shakespeare nu s-a mulțumit cu rolul de dramaturg colportor, ci a revoluționat condiția scriitoricească a breslei prin creații originale care au pus bazele teatrului modern.

De remarcat că adevăratul debut al dramaturgului William Shakespeare a avut loc la Blackfriars cu comediile: Doi tineri din Verona (1589) și Îmblânzirea scorpiei (1590), urmate de dramele istorice naționale legate de Henric VI și Richard III sau de cele antice, precum Titus Andronicus și capodopera Romeo și Julieta. Un moment important survine în 1594 când el este acceptat ca membru al trupei cu drepturi depline, an în care i se joacă Comedia erorilor și Zadarnicele chinuri ale dragostei, Visul unei nopți de vară... Piesa cu care Shakespeare face trecerea în 1599 de pe malul drept al Tamisei, pe cel stâng, adică de la Blackfriars, la Globe a fost Mult zgomot pentru nimic.

Anul 1599, cunoscut îndeobște ca fiind acela de fondare a teatrului Globe, este de fapt o refondare, la care Shakespeare se implică, de această dată având o poziție privilegiată. Deși cunoscuse o viață tumultuoasă, legată de boemă, glorie, privațiuni, diverse excese libertine și de ocultism, omul Shakespeare a fost totuși foarte echilibrat, el având și un foarte acut simț al realităților socio-economice. În acest context, dar și împins de moartea fiului său, el se va reîntoarce în fie- 
care sezon de relaxare estivală la Stratford, pentru a controla registrele contabile ținute de soție la investițiile lui imobiliare de acasă, dar și pentru a supraveghea progresele în educația celor două fete.

Dar și la Londra, Shakespeare a dat dovadă de un spirit managerial remarcabil: pe parcursul unui deceniu, cât activase la Blackfriars, dramaturgul strânsese o sumă considerabilă de pounds / lire pe care a investit-o în mod judicios în momentul cel mai propice. Odată cu fondarea lui The Globe, Shakespeare devine coproprietar și acționar prin achitarea $12,5 \%$ din costurile de reconstrucție ale teatrului pe malul stâng al Tamisei, iar, ulterior, director ${ }^{5}$. În noua sa ipostază, Shakespeare marchează debutul din 1599 al noului teatru printr-o pleiadă de creații remarcabile: Henry V, Iulius Cezar, Cum vă place și prima versiune din Hamlet, interpretate de trupa „Lord Chamberlain’ Men“ (ce va deveni din 1603, în timpul lui Jacob I, „The King’s Men“). De fapt, cu această trupă va colabora dramaturgul și pentru montarea celorlalte creații, tragedii precum: Othello, Regele Lear, Macbeth sau comedii: Cum vă place, A Douăsprezecea noapte, sau așa-numitele „piese problematice“, în sens de „echivoce“: Totu-i bine când se termină cu bine; Măsură pentru măsură; Trolius și Cresida, la care se pot adăuga și altele (Povestea unei nopți de iarnă etc.). Shakespeare se va retrage de pe scenă după 1609, an în care și-a surprins publicul sub numele de... „Shake Speares“6 - autor de Sonete, pentru ca în 1611 să renunțe la condiția de londonez, pentru a se întoarce în provincialul Stratford. Momentul despărțirii va fi marcat în mod simbolic prin două testamente - nu unul, cum se consideră îndeobște - complementare: unul „alb“ și optimist, iar celălalt „negru“ și pesimist. Este vorba, desigur, de Furtuna ce va fi însoțită de scoaterea pe scenă din sertarul dramaturgului a „piesei blestemate“: Macbeth (scrisă încă din 1606, dar „ținută la sertar“).

\section{Ibidem.}

6. „Shake Speares / SONNETS. / Never before Imprimed. / AT LONDON / by G. Eld for T.T. and are / to be folde by William Afpley. / 1609“ - folio. 
Trupa de la Globe îi va mai interpreta până în 1613 alte trei piese (scrise se pare însă în colaborare cu succesorul său - John Fletcher). În acel an, teatrul Globe a fost cuprins de un incendiu devastator în care s-au pierdut toate manuscrisele aflate acolo, inclusiv cele ale lui Shakespeare. Reconstituirea rapidă a clădirii după numai un an, cu ajutorul și al lui Richard Burbage, nu a putut însă readuce la lumină textele originale ale lui Shakespeare, urmând ca acestea să fie reconstituite din memoria prodigioasă a actorilor vremii și publicate postum în volumul First Folio (1623), ce cuprindea doar 20 de piese.

În 1616, Willam Shakespeare își face testamentul în deplină stare de sănătate, dar decedează (după cum susține episcopul local John Ward în jurnalul său ${ }^{7}$ ) în scurt timp, ca urmare a unei petreceri prelungite cu doi scriitori prieteni ce veniseră de la Londra să-l viziteze (Drayton și Ben Jonson).

Mai mare cu șapte ani decât Will, Ann Shakespeare i-a supraviețuit soțului cu încă pe atât...

\section{Istoria și istoriile lui Shakespeare}

„Ca dramaturg, Shakespeare a folosit, la rândul său, o serie de subiecte din literatura renascentistă italică, din mitologia grecolatină, din istoria relativ recentă a Angliei (a îmbinat tradiția dioramelor istorice cu adaptarea datelor din Cronicile lui Hall ${ }^{8}$ - 1548 și Holinshed - 1587), dar și din memoria orală. Numai că doar teatrul său a fost capabil de a produce o revoluție culturală (în cadrul teatrului elisabetan - n.n.), inclusiv la nivelul dreptului de autor, pentru că a fost creat sub semnul unei originalități ce a implicat pentru prima dată multiple niveluri ale scriiturii.

7. A. L. Rowes, Shakespeare: A Biography, Harper \& Rowes, New York, 1963 și S. Schoenbaum, Shakespeare's Lives, Oxford University Press, Oxford, 1991, apud: https://en.wikipedia.org/wiki/William_Shakespeare, consultat la 1.10. 2020.

8. Cronica acestuia i-a servit ca sursă de documentare lui Shakespeare, în afara „dioramelor“ istorice naționale propriu-zise, și pentru adaptările libere din: Regele Lear, Macbeth și Cymbelyne. 
Intenția declarată a operei shakespeariene a fost aceea de a distra publicul, dar și de a glorifica familia Tudorilor, strămoșii reginei Elisabeta I, care prin ea s-au impus pe fondul rivalităţilor din Războiul celor Două Roze (1455-1485) între casele Trandafirului Alb, de York, și cel Roșu, de Lancaster“.9 În realitate, fusese vorba doar de încetarea războaielor interne distrugătoare pentru ambele clanuri, prin intermediul unui armistițiu diplomatic realizat prin căsătorirea lui Henric al VII-lea (Lancaster) cu Elisabeta de York. Cum Artur, fiul lor cel mai mare ce trebuia să moștenească conform Legii salice Tronul Angliei, următorul, Henric, s-a dedicat inițial unei vieți intelectuale. Dar, în urma morții în adolescență a lui Arthur, Henric a trebuit să preia Coroana, ceea ce i-a scos în evidență aspecte contradictorii de caracter: militantismul asiduu pentru unitatea și supremația în lume a Albionului, dar și înșiruirea mai multor neveste cu care s-a putut căsători după ieșirea Protestantă de sub jurisdicția papală, urmată de crearea Anglicanismului și trecerea la prigoana catolicilor... Din căsătoria agitată lui Henric al VIII-lea cu Anne Boleyn, cea de-a doua soție din cele șase (nu opt, cum susține legenda), de care s-a despărțit prin trimiterea acesteia la eșafod, se născuse însă aceea care urma să devină regina Elisabeta I. Dar rivalitățile nu au încetat, dând naștere intrigilor sângeroase. Verișoara Elisabetei, Maria Stuart, va încerca să o uzurpe, așa că finalmente Elisabeta a trimis-o la eșafod. De dincolo de moarte, Maria Stuart și-a luat însă o „revanșă“: după decenii, fiul ei, Jacob I, i-a urmat Elisabetei pe tronul Angliei...

„Această preocupare (regalistă - n.n.) a scriitorului este explicabilă, atât din perspectiva respectului sincer faţă de monarhia britanică, dar și ca o formă de captatio benevolentiae și a protecției din partea Curții regale, implicit a publicului. În plus, sosirea lui Shakespeare la Londra a coincis cu urca-

9. Cristian Stamatoiu, Istoria antropologică a activării reflexului teatral (O viziune holistică asupra civilizației scenei în interconexiune cu mentalul colectiv continuu), Eikon și Școala Ardeleană, București și Cluj-Napoca, 2015, p. 148. 
rea pe Tronul Angliei a Elisabetei I în 1588, ceea ce i-a permis să fie martorul unei epoci istorice de legendară dezvoltare“. ${ }^{10}$

Numai că, după 1603, odată cu venirea la putere a succesorului ei, Jacob I, situația s-a complicat, pentru că noul rege era fiul Mariei Stuart a Scoției, pe care verișoara ei Elisabeta I o trimisese la eșafod... Dintr-o dată, Shakespeare a fost deci nevoit să schimbe obiectul admirației sale istorice dinspre Tudori, spre șirul de opt cavaleri Stuarți de la care se revendica Jacob. Schimbarea de azimut s-a efectuat însă foarte diplomatic, prin așezarea personajului pozitiv Banquo din Macbeth exact în descendența unui astfel de ilustru șir de Lorzi. Damnarea lui Macbeth și a soției sale au fost de asemenea asociate cu condamnarea inițiatorilor „Complotului trădător al prafului-de-pușcă“ prin care se plănuia aruncarea în aer a Parlamentului la sosirea lui Jacob I. Finețea psihologică și diplomația au fost duse până acolo, încât amorsarea conflictului din Macbeth prin apariția celor trei vrăjitoare venea în întâmpinarea pasiunii regelui pentru ocultism! Dar, în ansamblu, susținerea indirectă a regalității a fost asociată cu un mesaj politic hotărât, omologul dramatic al noului rege (Banquo) luptând cu tirania cuplului Macbeth pentru salvgardarea libertății, fapt ce se pare că nu a prea atenuat excesele autoritare ale lui Jacob I...

„Mai apoi, venea intenția critică a unui comentariu fabulistic la adresa vieții de Curte din vremea sa, folosindu-se însă de parabole pentru a nu fi condamnat de putere pentru dezvăluirea unor intrigi de culise sau de ,secrete à la Polichinelle“. Desigur, aceste referințe anecdotice s-au pierdut odată cu memoria colectivă a contemporanilor lui Shakespeare, ceea ce nu afectează însă cu nimic valoarea operei sale, deoarece ea nu rezidă în dezvăluiri ale intrigilor de la Curtea Elisabetei I și, ulterior, a lui Iacob I, ci din sondarea eternului uman de oricând și de oriunde. În profunzimea textului său, Shakespeare a răsădit profunde meditații asupra raporturilor dinamice dintre individ și sine, în contextul trăirilor erotico-tanatice, legate îndeosebi de obsesia deținerii și exercitării

10. Ibidem. 
puterii politice absolute. Tensiunea dramatică a acestor texte nu provine din desfășurarea subiectului, care era îndeobște larg cunoscut; abordarea shakespeareană era și este fermecătoare, datorită dezbaterii implicite de idei împletite perfect cu tehnica scriitoricească. Straturile semantice ${ }^{11}$ ale scriiturii shakespeariene degajă invariabil rezistența față de tentația dezumanizării, în timp ce stilul său literar miza pe: tehnica oratorică a unor exerciții când de admirație, când de contestație; alternarea cu naturalețe în somptuoase dezbateri a argumentelor și contraargumentelor față de același referent; relativizarea binelui și a răului, totul (de)curgând într-o magică fluență“12 a rimării ideatice și a vorbirii cu meșteșug.

\section{*}

„Cele 37 de creații shakespeariene formează o unitate, putându-se vorbi în acest caz de un sistem Shakespeare. Dramaturgia „Marelui Will“ este genială, pentru că el a avut primul intuiția de a defaza tematica subiectului față de aceea a semnificației de profunzime. Sub aparența unui conflict lesne de asimilat de către conștiința publicului, sistemul poate degaja mereu noi semnificații secunde (cât și mize existențiale neașteptate), asigurând celor două planuri un caracter universal și etern valabil, atât în timp, cât și în spațiu. “13

\section{Bibliografie:}

Allain, Paul; Harvie, Jean, Ghidul Routledge de teatru și performan$c e$, traducere de Cristina Modreanu, Ilinca Tamara Todoruţ, București, Editura Nemira, 2012.

BARBA, Eugenio; Savese, Nicola, Cele cinci continente ale teatrului. Fapte și legende din cultura materială a actorului, traducere din limba italiană de Vlad Russo, București, Nemira, 2018.

BEST, Michael, Shakespeare's Life and Times [Viața pe timpurile lui Shakespeare, en.], Internet Shakespeare Edition, la 1.03.2020.

11. Inițial: „Foietajul semantic al scriiturii“ - n.n.

12. Ibidem, pp. 148-149.

13. Ibidem, p. 149. 
BRook, Peter, Împreună cu Shakespeare, traducere de Anca Măniuțiu, Craiova, Editura Aius, 2003.

KотT, Jan, Shakespeare, contemporanul nostru, traducere de Anca Livescu și Teofil Roll, București, Ed. pentru Literatură Universală,1969.

LĂZĂRESCU, Dan, Introducere în shakespearologie, București, Editura Univers, 1974.

LEVIȚCHI, Leon, Istoria literaturii engleze și americane (ed. II), vol. I, București, Editura ALL, 1998.

RusSELL Brown, John, The Oxford Illustrated History of the Theatre [Istoria ilustrată Oxford a teatrului, en.], Oxford, Oxford University Press, 2001.

STAMATOIU, Cristian, Istoria antropologică a activării reflexului teatral (O viziune holistică asupra civilizației scenei în interconexiune cu mentalul colectiv continuu), Eikon și Școala Ardeleană, București și Cluj-Napoca, 2015.

\section{Resurse web}

https://www.shakespeare.org.uk/explore-shakespeare/shakespedia/ shakespedia-index;

https://www.opensourceshakespeare.org/search/search-advanced. php;

http://absoluteshakespeare.com; 